\title{
The status and predictors of hypertension preventive nutritional behaviors in adolescents based on the constructs of the Theory of Planned Behavior
}

\author{
Mohammad Matlabi ${ }^{1}$, Reza Esmaeili ${ }^{2}$, Mahdi Moshki ${ }^{3}$, Afsaneh Ranaei ${ }^{4}$, Alireza Haji ${ }^{5}$, Rahele Mehrabi ${ }^{6}$
}

${ }^{1}$ Assistant Professor, Department of Public Health, School of Public Health, Gonabad University of Medical Sciences, Gonabad, Iran

${ }^{2}$ Social Development \& Health Promotion Research Center" and "Public Health Department, Health Faculty", Gonabad University of Medical Sciences, Gonabad, Iran

${ }^{3}$ Associate Professor, Department of Public Health, School of Public Health, Gonabad University of Medical Sciences, Gonabad, Iran

${ }^{4}$ M.Sc. Student, Department of Health Education and Health Promotion, School of Public Health, Gonabad University of Medical Sciences, Gonabad, Iran

${ }^{5}$ M.Sc. Student, Department of Health Education and Health Promotion, School of Public Health, Gonabad University of Medical Sciences, Gonabad, Iran

${ }^{6}$ M.Sc. in Medical Library and Information Sciences, Gonabad University of Medical Sciences, Gonabad, Iran

\section{Type of article: Original}

\begin{abstract}
Background: Malnutrition is an important factor affecting hypertensive incidence. Since the unhealthiest nutritional behaviors are rooted in childhood attitudes and experiences, applying educational interventions to these age groups will be most useful in the formation of preventive nutritional behaviors.

Objective: To determine the predictive power of the TPB on hypertension in junior high-school students.

Methods: The present cross-sectional study was conducted on 160 junior high-school students in Kashmar, Iran in academic year commencing 2-13-2014, selected through random sampling. The participants completed a researcher-made questionnaire consisting of a demographic information form and a section to evaluate the constructs of the TPB. The data collected were analyzed in SPSS-16 using the correlation Wilcoxon statistics test, the one-way ANOVA and multiple linear regression analysis.

Results: The mean age of the students was 13.51. A total of $47 \%$ of the students had snacked on potato chips and cheese puffs, $45 \%$ had eaten high-fat foods and $51.2 \%$ had eaten cookies and chocolates within the past week. The variable of behavioral intention predicted $32 \%$ of the variations in preventive nutritional behaviors by itself. The Pearson product-moment correlation analysis found that hypertension preventive nutritional behaviors were significantly correlated with attitude $(\mathrm{p}<0.001, \mathrm{r}=0.38)$, perceived behavioral control $(\mathrm{p}<0.001, \mathrm{r}=0.38)$, and behavioral intention. Moreover, significant correlations were observed between subjective norms and attitude $(\mathrm{p}<0.028, \mathrm{r}=0.173)$, perceived behavioral control and attitude $(\mathrm{p}<0.003, \mathrm{r}=0.231)$, behavioral intention and attitude $(\mathrm{p}<0.001, \mathrm{r}=0.370)$, behavioral intention and subjective norms $(\mathrm{p}<0.030, \mathrm{r}=0.171)$ and between behavioral intention and perceived behavioral control $(\mathrm{p}<0.001, \mathrm{r}=0.484)$.

Conclusion: The examined students revealed an adequate adherence to preventive nutritional behaviors. Nutrition education interventions should be developed based on variables such as behavioral intention and its determinants, i.e. attitude, perceived behavioral control and subjective norms.

Keywords: Preventive nutritional behaviors, Theory of planned behaviors, Students, Hypertension
\end{abstract}

\section{Introduction}

Non-contagious diseases including cardiovascular diseases, brain attack, diabetes, cancer and chronic respiratory diseases are the main causes of death and the burden of diseases in the world. Out of 58,000,000 deaths annually,

\section{Corresponding author:}

Alireza Haji, Department of Health Education and Health Promotion, School of Public Health, Gonabad University of Medical Sciences, Gonabad, Iran. Tel: +98.9153329758, Fax:+98.5157223401, Email: hajjia2@mums.ac.ir Received: April 09, 2017, Accepted: September 27, 2017, Published: January 2018 iThenticate screening: July 23, 2017, English editing: January 12, 2017, Quality control: January 14, 2017 (C) 2018 The Authors. This is an open access article under the terms of the Creative Commons Attribution-NonCommercialNoDerivs License, which permits use and distribution in any medium, provided the original work is properly cited, the use is non-commercial and no modifications or adaptations are made. 
nearly 35,000,000 cases are because of the mentioned diseases. Among the non-contagious diseases, cardiovascular diseases are the most common ones and they account for one fourth of the deaths in the world. In our country, cardiovascular diseases account for $40 \%$ of deaths, and about $10.5 \%$ of the burden of diseases is due to those diseases and it takes exorbitant national costs to cure these diseases (1). Today, hypertension and its complications comprise a significant health problem in the modern world and are considered precursors to many diseases such as myocardial infraction, stroke, congestive heart failure, advanced chronic kidney disease and peripheral vascular diseases $(2,3)$. According to studies, the global economic burden of this disease was about $\$ 370$ million in 2012 , making up for $10 \%$ of global total health expenditure (4). Hypertension is rooted in childhood and adolescence, as most people with childhood and adolescent hypertension continue to suffer from this condition in adulthood (5). The prevalence of hypertension varies across different countries and has been reported as $1 \%$ in children and $3 \%$ in adolescents (2), although, some reports have estimated it to range from $5 \%$ to $11 \%$ (6). Hypertension is caused by different factors; however, poor nutritional behaviors are among the main factors contributing to this condition. Furthermore, behavioral characteristics such as poor nutrition patterns formed in adolescence cause many complications, such as adulthood mortality. In other words, many healthy and unhealthy behaviors established during this stage manifest themselves as fixed patterns into adulthood $(7,8)$. As an adolescent, the individual is now responsible for his own nutrition patterns, attitudes and behaviors, and attitudes tend to play a key role in the continuation and maintenance of a wide range of nutrition habits and behaviors (4). The physical and psychological changes developed in adolescence make up the adolescent's nutritional health; if these changes are ignored, they will cause adverse consequences such as anorexia and overeating, and the adolescent will become underweight or overweight as a result $(8,9)$. Adolescents account for one-fifth of the total population of the world. Almost $84 \%$ of this age group lives in developing communities. In Iran, the 10-19 age group makes up more than $20 \%$ of the total population. The health and progress of this group is undoubtedly integral to the socioeconomic future of the country. Nevertheless, research suggests that this age group suffers from low or moderate levels of nutritional awareness in different aspects (10). In one study, Mirmiran found that only a small percentage of adolescents in Tehran have proper nutritional behaviors and most of their nutritional behaviors are not guided by nutritional awareness $(4,7)$. The rapid and significant changes in nutrition patterns and lifestyles in different communities facilitate the development of many diseases such as hypertension, and have thus become the cause of premature mortality in developed and developing countries $(11,12)$. Changes in eating habits contribute significantly to this pattern and nutritional factors are currently known as risk factors for the development of non-contagious diseases (7). Emphasizing the awareness, attitude and performance of this group is the main prerequisite of health promotion programs in society. Meanwhile, theories are capable of determining potentially-alterable personal characteristics, beliefs and values associated with different health behaviors. The TPB is a principal theory used in different studies to determine the attitudes and beliefs associated with food selection $(13,14)$. The results of meta-analyses conducted on the TPB have shown that the constructs of this theory can properly predict intention and ultimately, behavior ( 15 , 16). According to this theory, the primary factor involved in determining behavior is the individual's intention in performing that behavior. The second factor involved is the individual's perception of the social pressures exerted by significant others for doing or not doing that behavior (social norms). The third factor involved is the individual's perception of the ease or difficulty of performing that behavior, i.e. perceived behavioral control, which consists of internal and external factors. These factors can inhibit or facilitate a behavior $(13,17)$. The exact contribution of each of the factors to the prediction of behavior differs depending on the type of behavior in question and the study population (18). A review of literature shows that the majority of studies on this subject are focused on the relationship between fruit consumption and the incidence and prevalence of some diseases, and no studies have examined the effects of hypertension preventive nutritional behaviors in adolescents using the TPB (19-21). The present study was therefore conducted in Kashmar, Iran, to investigate the status and the predictive factors of hypertension preventive nutritional behaviors in adolescents based on the constructs of the TPB.

\section{Material and Methods}

\subsection{Research design}

The present cross-sectional study was conducted on 160 students in Kashmar, Iran, in 2013. The study population was all the junior high school students of Kashmar in the academic year of 2013-2014. Six high schools have been randomly selected for the study, including girls and boys.

\subsection{Inclusion criteria}

The following were set as the inclusion criteria: 1) being in grade 2 or 3 of junior high school, 2) being 12 to 13 years old, 3) nonstop presence from the beginning of the academic year, and 4) having Iranian nationality and being interested in the study. 


\subsection{Sampling}

\subsubsection{Sample size}

Based on this equation as well as the results of similar studies (22), in which the standard deviation obtained for preventive behaviors was 0.6 , the study sample size was calculated as 150 with a precision of 0.05 and an acceptable error rate of 0.1 . A total of 160 eligible students were ultimately selected to account for potential sample losses and the potential submission of incomplete questionnaires.

\subsubsection{Sampling method}

The subjects were selected through multistage random sampling. At the first stage of sampling, two all-girl and two all-boy middle schools (junior high-schools) were chosen and 80 subjects were selected from each school based on the number of eligible students in each class so as to complete the questionnaires.

\subsection{Instrument and data collection}

The questionnaire used in this study investigated the students' personal information, including age, gender, parental education, parents' occupation, type of residence, household size, average monthly income and allowance, and examined the constructs of the TPB, including attitude, subjective norms, perceived behavioral control, behavioral intention and behavior. Due to the lack of a standard questionnaire on this subject, the researchers developed their own questionnaire using relevant books, studies and references and in accordance with Icek Ajzen's website on the TPB. Cronbach's alpha values were calculated to confirm the reliability of each of the constructs. Behavioral intention (six items), attitude (11 items), subjective norms (five items) and perceived behavioral control (five items) were assessed based on a five-point Likert scale and with responses ranging from 1 (completely disagree) to 5 (completely agree). Ultimately, behavior was assessed with eight items, two of which were scored based on the Likert scale and the remaining six by 'yes' ( 1 point $)$ and 'no' $(0$ points $)$ responses. The constructs were assessed directly and the questionnaire was distributed among ten experts and 20 non-participating adolescents and two nutritionists to review and respond to the items and to determine their clarity. Based on the reviewers' opinions and suggestions, modifications were made to further clarify the items. In addition, ten experts reviewed and confirmed the questionnaire's face and content validities and their comments were implemented to further improve the questionnaire. A test-retest was performed with an interval of two weeks on 20 non-participating samples in order to determine the reliability and the stability coefficient of the questionnaire. The reliability of the items pertaining to the constructs of the TPB was confirmed by measuring their Cronbach's alpha, which was reported as $92.7 \%$ for attitude, $88.8 \%$ for subjective norms, $86.6 \%$ for perceived behavioral control, $86.7 \%$ for behavior and $86.5 \%$ overall. The questionnaire took 15 minutes to be completed. The study sample size was calculated based on the two objectives of the research, i.e. estimating the mean and the ratio. The required sample size calculated through the equation for estimating the mean was higher, and this estimation thus formed the basis of the calculations.

\subsection{Statistical analysis}

Data were analyzed by SPSS-16.5 (SPSS Inc., Chicago, Illinois, USA), using descriptive statistics, Pearson productmoment correlation, and multiple linear regression. $\mathrm{P}<0.05$ was set as the level of statistical significance. The normal distribution of the data was confirmed by the Kolmogorov-Smirnov test.

\subsection{Ethics}

Before beginning the study, permissions were obtained from Gonabad University of Medical Sciences (Ref. No.: GMU.REC.1392.59) and Kashmar's Department of Education to arrange a time for the students to fill out the questionnaires. The students were briefed on the study objectives and ensured of the confidentiality of their information, and then decided whether they wanted to participate in the study or be excluded from it; nevertheless, all the eligible candidates showed interest in participating in the study.

\section{Results}

The students ranged from 12 to 15 in age and had a mean age of 13.51 (Table 1). In terms of birth order, $41.25 \%$ of the subjects were first-born. The majority of the subjects had fathers who were self-employed $(62.5 \%)$ and mothers who were housewives $(90.62 \%)$. A total of $71.87 \%$ of the fathers and $70.62 \%$ of the mothers had below high-school level education. A total of $70 \%$ of the subjects estimated their family income and economic status as moderate while $16.8 \%$ predicted it as high. A total of $58 \%$ of the subjects were enjoyed eating pizza and sandwiches while only $13 \%$ did not like pizza and sandwiches at all. Moreover, 55.4\% of the subjects had a strong liking for chips and cheese puffs. According to the study findings, $47 \%$ of the students had snacked on chips and cheese puffs within the previous week and $57 \%$ within the previous month; $45 \%$ had had high-fat foods within the previous week and $55.6 \%$ within the previous month; and 51.2\% had had cookies and chocolates within the previous week and 55.6\% 
within the previous month. A total of $68.1 \%$ of the students were in favor of having soft drinks with their meals and $64 \%$ had no dietary plans. A total of $87 \%$ of the students liked dairy and $68 \%$ liked to drink milk every day. A total of $94.3 \%$ of the students were also in favor of incorporating vegetables into their meals. The number of items of questionnaire and the mean scores of the studied variables are presented in Table 2. The Pearson product-moment correlation analysis (Table 3) found hypertension preventive nutritional behaviors to be significantly correlated with attitude $(\mathrm{p}<0.001, \mathrm{r}=0.38)$, perceived behavioral control $(\mathrm{p}<0.001, \mathrm{r}=0.38)$ and behavioral intention. Moreover, significant correlations were observed between subjective norms and attitude $(\mathrm{p}<0.028, \mathrm{r}=0.173)$, perceived behavioral control and attitude $(\mathrm{p}<0.003, \mathrm{r}=0.231)$, behavioral intention and attitude $(\mathrm{p}<0.001, \mathrm{r}=0.370)$, behavioral intention and subjective norms $(\mathrm{p}<0.030, \mathrm{r}=0.171)$ and between behavioral intention and perceived behavioral control $(\mathrm{p}<0.001, \mathrm{r}=0.484)$. As shown in Table 4, the regression model showed that, of the constructs that had significant correlations with hypertension preventive nutritional behaviors (i.e. attitude, perceived behavioral control and behavioral intention), behavioral intention alone predicted $32 \%$ of the variations in hypertension preventive nutritional behaviors.

Table 1. The demographic details of the study participants

\begin{tabular}{|c|c|c|c|}
\hline Variable & Unit of Measurement & $\mathrm{n}$ & $\%$ \\
\hline \multirow[t]{3}{*}{ Age (year) } & $13-14$ & 60 & 37.5 \\
\hline & $14-15$ & 81 & 50.6 \\
\hline & 15 & 7 & 4.3 \\
\hline \multirow[t]{3}{*}{ Birth Order } & First-born & 66 & 41.25 \\
\hline & Second-born & 38 & 23.75 \\
\hline & Third-born and higher orders & 56 & 35 \\
\hline \multirow[t]{5}{*}{ Father's Occupation } & Unemployed & 1 & 0.6 \\
\hline & Office Employee & 35 & 21.8 \\
\hline & Laborer & 20 & 12.5 \\
\hline & Business and Trade & 100 & 62.5 \\
\hline & Other & 4 & 2.5 \\
\hline \multirow[t]{4}{*}{ Mother's Occupation } & Office Employee & 7 & 4.37 \\
\hline & Laborer & 2 & 1.25 \\
\hline & Business and Trade & 6 & 3.75 \\
\hline & Housewife & 145 & 90.62 \\
\hline \multirow[t]{3}{*}{ Father's Education } & Below High School Level & 115 & 71.82 \\
\hline & High School Diploma & 19 & 11.87 \\
\hline & University Education & 26 & 16.25 \\
\hline \multirow[t]{3}{*}{ Mother's Education } & Below High School Level & 113 & 70.62 \\
\hline & High School Diploma & 29 & 18.12 \\
\hline & University Education & 18 & 11.25 \\
\hline \multirow[t]{3}{*}{ Type of Residence } & Owner & 139 & 86.87 \\
\hline & Renting & 18 & 11.25 \\
\hline & Corporate Housing & 3 & 1.78 \\
\hline \multirow[t]{3}{*}{ Income Status } & Low & 112 & 70 \\
\hline & Moderate & 21 & 13.1 \\
\hline & High & 27 & 16.8 \\
\hline
\end{tabular}

Table 2. The number of items and their mean and standard deviation in the study subjects in relation to the constructs of the TPB and hypertension preventive nutritional behaviors

\begin{tabular}{|l|l|l|l|}
\hline Model Construct & Number of Items & Mean of scores & SD \\
\hline Attitude & 11 & 28.27 & 6.13 \\
\hline Subjective Norms & 5 & 12.58 & 2.98 \\
\hline Perceived Behavioral Control & 5 & 12.81 & 2.97 \\
\hline Behavioral Intention & 6 & 16.02 & 4.61 \\
\hline Behavior & 8 & 8.00 & 3.22 \\
\hline
\end{tabular}


Table 3. The correlation coefficients matrix of the TPB constructs and hypertension preventive nutritional behaviors

\begin{tabular}{|l|l|l|l|l|l|}
\hline \multicolumn{2}{|l|}{ Model Construct } & Attitude & $\begin{array}{l}\text { Subjective } \\
\text { Norms }\end{array}$ & $\begin{array}{l}\text { Perceived } \\
\text { Behavioral Control }\end{array}$ & $\begin{array}{l}\text { Behavioral } \\
\text { Intention }\end{array}$ \\
\hline \multirow{2}{*}{ Attitude } & Correlation Coefficient & 0.380 & & & \\
\cline { 2 - 6 } & Level of Significance & 0.001 & & & \\
\hline \multirow{2}{*}{ Subjective Norms } & Correlation Coefficient & 0.173 & & & \\
\cline { 2 - 7 } & Level of Significance & 0.028 & & & \\
\hline \multirow{2}{*}{$\begin{array}{l}\text { Perceived Behavioral } \\
\text { Control }\end{array}$} & Correlation Coefficient & 0.234 & 0.146 & & \\
\hline & Level of Significance & 0.003 & 0.065 & & \\
\hline \multirow{2}{*}{ Behavioral Intention } & Correlation Coefficient & 0.370 & 0.171 & 0.489 & \\
\cline { 2 - 6 } & Level of Significance & 0.001 & 0.030 & 0.001 & 0.001 \\
\hline Behavior & Correlation Coefficient & 0.380 & 0.056 & 0.381 & 0.001 \\
\cline { 2 - 6 } & Level of Significance & 0.001 & 0.480 & & \\
\hline
\end{tabular}

Table 4. The results of the linear regression model between hypertension preventive nutritional behaviors and the TPB constructs

\begin{tabular}{|l|l|l|l|l|l|}
\hline Variable & $\mathrm{R}^{2}$ & $\mathrm{~B}$ & $\mathrm{SE}$ & Beta & $\mathrm{p}$-value \\
\hline Allowance & 0.01 & 0.745 & 0.558 & 0.106 & 0.180 \\
\hline Family Income & 0.001 & 0.027 & 0.25 & 0.008 & 0.917 \\
\hline Attitude & 0.16 & 0.237 & 0.042 & 0.409 & 0.002 \\
\hline Subjective Norms & 0.002 & 0.058 & 0.095 & 0.049 & 0.540 \\
\hline Perceived Behavioral Control & 0.16 & 0.482 & 0.087 & 0.403 & 0.001 \\
\hline Behavioral Intention & 0.32 & 0.480 & 0.056 & 0.558 & 0.002 \\
\hline
\end{tabular}

\section{Discussion}

Adolescent population growth and the particular problems of this age group comprise one of the problems with which developing countries such as Iran are faced. Examining nutritional behaviors in the group of junior highschool students revealed $47 \%$ to have snacked on chips and cheese puffs within the past week and $57 \%$ within the past month, which is consistent with the results of a study conducted by Delvarianzadeh, in which $56 \%$ were in favor of chips (23). Moreover, $68.1 \%$ of the students were in favor of having soft drinks with each of their meals, which is consistent with the results of a study in 2007 on adolescent girls in Hawaii, which found food intake in 51\% of this group to not be based on the food pyramid and also showed a significant increase in the use of sweetened soft drinks and sugar. Mirmiran et al. also examined nutritional behaviors in a group of middle-school students and reported their nutritional status as moderate (24-26). According to Pi-Lin, inadequate or incorrect nutritional information exposes adolescents to poor food selection and nutritional behaviors (27). In the present study, $45 \%$ of the students had consumed high-fat foods within the past week and $56 \%$ within the past month, which is relatively consistent with the results of other studies on the subject (28). The present study reported the consumption of pizza, sandwiches and chips in $27.6 \%$ of the students, which is consistent with the results of the other study in which $27.6 \%$ of middle-school students consumed fast foods and other pre-processed foods two to three times per week (29). While the present study found the daily consumption of milk to be $68 \%$, another study reported it as $35 \%$; this disparity may be justified by noting the free distribution of milk among the students in the present study. A study conducted by Wave on female adolescents in Minnesota also obtained contradictory results (30). The present study found $94.3 \%$ of its subjects to be in favor of incorporating vegetables into their every meal. As also shown by Gholipour and Delvarianzadeh (31), this attitude can highlight the role of students in increasing families' consumption of fruits and vegetables. In contrast to the present study, Lin found a distinct gap in information, attitude and nutritional behaviors, particularly in relation to the consumption of fruits and vegetables (32), which indicates the weak attitudes of this age group. In terms of subjective norms, the present study found that $45 \%$ of the parents had been effective in their children's nutritional behaviors; this finding suggests that, besides the parents, other people such as friends and teachers can also have a role in determining the students' nutritional behaviors, which is perhaps caused by the sense of independence from parents that begins to form at this age. This finding is consistent with the results obtained in similar studies $(33,34)$. The present study found no significant relationships between preventive nutritional behaviors and the fathers' level of education, the mothers' level of education, the fathers' occupation and the mothers' occupation. This finding is consistent with the results obtained by Dehdari et al. $(31,35)$. Other studies, however, reported this difference to be significant, as an increase in the education and job status of the head of the household reduced the consumption of high-calorie food groups such as bread, cereal and 
sugar and added to the consumption of fruits and vegetables in the family (36). In another study, Dastgiri also showed that an increase in the income and education of the head of the household enhanced the family's food security and reduced their food insecurity. Ultimately, food insecurity is related directly to reduced fruit and vegetable consumption (37). After determining the correlation between hypertension preventive nutritional behaviors and the TPB constructs, the constructs that had positive correlations with this variable were entered into the regression model. In the first model, behavioral intention alone predicted $32 \%$ of the variations in preventive nutritional behaviors, which is consistent with the results of the study by Dehdari et al. (31). Similar studies reported the predictive power of behavioral intention as $50 \%$ and $64 \%$ for eating fast food and having breakfast, in respective order $(17,38)$. Studies have shown that, at best, the TPB has a moderate value in the prediction of behavior, and adding other constructs such as past behaviors, i.e. past food habits can enhance the theory's predictive power (39). According to Ajzen, intention cannot lead to behavior in and by itself, and there is a gap between intention and behavior, which can be overcome by the incorporation of constructs such as past behaviors (13). A limitation of the present study was the lack of similar studies on the subject to form the basis of comparison. Another limitation was, the psychological and intellectual difference and the motivation of individuals who can be effective on how to respond.

\section{Conclusions}

Given the results obtained in this study and the role of the TPB in hypertension preventive nutritional behaviors in adolescents, an appropriate educational program should be developed based on the TPB to improve hypertension preventive nutritional behaviors. It is useful that the future studies examine this model in other preventive behaviors.

\section{Acknowledgments:}

This paper is the result of M.Sc. thesis in health education and health promotion at Gonabad University of Medical Sciences. This study was funded by Gonabad University of Medical Sciences. Hereby, the authors would like to express their gratitude to all those who helped with the implementation of this research project, especially Kashmar's Department of Education and all the school heads, teachers and students who helped conduct the study.

\section{Conflict of Interest:}

There is no conflict of interest to be declared.

\section{Authors' contributions:}

All authors contributed to this project and article equally. All authors read and approved the final manuscript.

\section{References:}

1) Hojatzadeh L, Smvat T. Guide to Blood Pressure measurement. Tehran: Ministry of health and Medical sciences; 2012.

2) Daniels SR. Consultation with the specialist. The diagnosis of hypertension in children: an update. Pediatr Rev. 1997; 18(4): 131-5. doi: 10.1542/pir.18-4-131. PMID: 9100449.

3) Burt VL, Whelton P, Roccella EJ, Brown C, Cutler JA, Higgins M, et al. Prevalence of hypertension in the US adult population: results from the third National Health and Nutrition Examination Survey; 1988-1991. Hypertension.1995; 25: 305-13. doi: 10.1161/01.HYP.25.3.305. PMID: 7875754.

4) Turconi G, Guarcello M, Maccarini L, Cignoli F, Setti S, Bazzano R, et al. Eating habits and behaviors, physical activity, nutritional and food safety knowledge and beliefs in an adolescent Italian population. J Am Coll Nutr. 2008; 27(1): 31-34. doi: 10.1080/07315724.2008.10719672. PMID: 18460479.

5) Weber C. Do Adults and Children Share Risk Factors for High Blood Pressure Available from: http://highbloodpressure.about.com.

6) Sorof J, Daniels S. Obesity hypertension in children: A problem of epidemic proportions. Hypertension. 2002; 40: 441-7. doi: 10.1161/01.HYP.0000032940.33466.12. PMID: 12364344.

7) Paknahad Z, Sharifi Rad G, Yazdani M, Hosseini S. Effect of nutrition education on knowledge and attitudes of city high school students in the academic year 2008-2007. J Health Res. 2010; 6(1): 73-8.

8) Mohebi S, Sharifirad GH, Shahsiah M, Botlani S, Matlabi M, Rezaeian M. The effect of assertiveness training on student's academic anxiety. J Pak Med Assoc. 2012 Mar;62 (3 Suppl 2):S37-41. PMID: 22768456

9) Khoshfetrat MR, Rahmani KH, Kalantari N, Ghafarpour M, Mehrabi Y, Ismailzadeh A. Evaluation and comparison of nutritional pattern And BMI in urban and rural male adolescence. Payesh. 2007; 6: 119-27. 
10) Esfarjani F, Golestan B, Derakhshani K, Rustai R, Rasuli B. Do the adolescence girls have the sufficient biometric parameters and appropriate knowledge among their nutrition? Pejouhandeh. 2005; 3: $183-9$.

11) Laquatra I. Nutrition for health and fitness. Kraus s food, nutrition and diet therapy. 11th ed. Philadelphia: W.B. Saunders; 2004: 558-94.

12) Sadrzadeh H, Atavi NA, Dorostimotlagh AR. Correlation of obesity with some nutritional behavior in Kerman high school girls. Payesh. 2007; 3: 193-9.

13) Ajzen I, Fishbein M. Understanding attitudes and predicting social behavior. New York: Prentice-Hall; 1980.

14) Tuorila H, Pangborn RM. Prediction of reported consumption of selected fat-containing foods. Appetite. 1988; 11(2): 81-95. doi: 10.1016/S0195-6663(88)80008-4.

15) Armitage CJ, Conner M. Efficacy of the Theory of Planned Behaviour: a meta-analytic review. Br J Soc Psychol. 2001; 40(Pt 4): 471-99. doi: 10.1348/014466601164939. PMID: 11795063.

16) Sheeran P. Intention-behaviour relations: A conceptual and empirical review. European Review of Social Psychology. New Jersey: John Wiley \& Sons; 2002: 1-36.

17) Wong CL, Mullan BA. Predicting breakfast consumption: an application of the theory of planned behaviour and the investigation of past behaviour and executive function. Br J Health Psychol .2009; 14(Pt 3): 489-504. doi: 10.1348/135910708X360719. PMID: 18808734.

18) Sharma M, Romas JA. Theoretical foundations of health education and health promotion. 1st ed. Boston: Jones and Bartlett; 2007: 116-36.

19) Adibi H, Ebrahimof S, Mortaz Hejri S, Saleh Omoom N, Arzaghi M, Hosseini S. Relationship between fruits and vegetables intake and bone mineral density in rural population surrounding Tehran. Med J Reproduction \& Infertility. 2009; 6(1): 69-78.

20) Hosseini F, Mirmiran P, Azizi F. Fruit and vegetable intake and the metabolic syndrome: Tehran lipid and glucose study. Iranian J Endocrinology \& Metabolism.2007; 9(3): 267-77.

21) Ebrahimof S, Hossein Nezhad A, Hooshyar Rad A, Rahmani M, Valaei N, Larijani B, et al. Fruit and vegetable intake and bone turnover markers in postmenopausal osteopenic women referring to bone densitometry unit of Shariati hospital during 2000-2004. Pejouhandeh J. 2006; 11(51): 159-65.

22) Fallah H, Hosseini M, Keshavarz SA. A study of the height, weight, Body Mass index (BMI) and intake of nutrients among 11- years -old Adolescent of nonprofit schools in Damghan city. Toloo E Behdasht. 2006; $5(3,4): 20-27$.

23) Delvarian-Zadeh M, Khosravi A, Taghavi NS, Sadeghian F, Bolbol-Haghighi N, Khatibi R. Nutritional Evaluation of Adolescent Middle School Girls in Shahroud. Journal of Knowledge \& Health. 2012; 7(1): 14-9.

24) Lee SK, Novotny R, Daida YG, Vijayadeva V, Gittel Sohn J. Dietary patterns of adolescent girls in Hawaii over a 2-year period. J Am Diet Assoc. 2007; 107(6); 956-61. doi: 10.1016/j.jada.2007.03.009. PMID: 17524716.

25) Hamayeli Mehrabani H, Mirimiran P, Alaiin F, Azizi F. Changes in Nutritional Knowledge, Attitude, and Practices of Adolescents in District 13 of Tehran after 4 Years of Education. Iranian Journal of endocrinology and metabolism. 2009; 11(3): 235-43.

26) Rahimi Z, Mohebi S, Yousefi Z, Kheirollahi F, Saraf P, Matlabi M. Analysis of Training Needs of Mothers on Exclusive Breastfeeding; a Study in Health Care Centers. International Journal of Pediatrics. 2016 Dec 1;4(12):4089-98.

27) Pei Lin H. Factors influencing students' decisions to choose healthy or unhealthy snacks at the University of Newcastle, Australia. J Nurs Res. 2004; 12(2): 83-91. doi: 10.1097/01.JNR.0000387492.16804.a3. PMID: 15208773.

28) Sharifirad GR, Yarmohammadi P, Azadbakht L, Morowatisharifabad MA, Hassanzadeh A. Determinants of Fast Food Consumption among Iranian High School Students Based on Planned Behavior. Journal of Obesity. 2013: 1-7.

29) Seo HS, Lee SK, Nam S. Factors influencing fast food consumption behaviors of middle-school students in Seoul: an application of theory of planned behaviors. Nutr Res Pract. 2011; 5(2): 169-78. doi: 10.4162/nrp.2011.5.2.169. PMID: 21556232, PMCID: PMC3085807.

30) Vue H, Reicks M. Individual and environmental influences on intake of calcium-rich food and beverages by young Hmong adolescent girls'. Nutr Educ Behav.2007; 39(5): 264-72. doi: 10.1016/j.jneb.2007.03.092.

31) Dehdari T, Kharghani Moghadam M, Mansouri T, Saki A. Survey of daily fruit consumption status among girl students who are living in dormitories and its predictors based on the theory of planned behavior constructs. Razi Journal of Medical Sciences .2013; 20(106): 10-19. 
32) Lin W,Yang HC, Hang CM, Pan WH. Nutrition knowledge, attitude, and behavior Of Taiwanese elementary schoolchildren elementary schoolchildren. Asia Pac J Clin Nutr. 2007; 2: S534-46.

33) Moore LV, Diez Roux AV, Nettleton JA, Jacobs DR, Franco M. Fast-food consumption, diet quality, and neighborhood exposure to fast food: the multi-ethnic study of atherosclerosis. Am J Epidemiol. 2009; 170(1): 29-36. doi: 10.1093/aje/kwp090. PMID: 19429879, PMCID: PMC2733038.

34) Pereira MA, Kartashov AI, Ebbeling CB, Van HL, Slattery ML, Jacobs DR, et al. Fast-food habits, weight gain, and insulin resistance (the CARDIA study): 15-year prospective analysis . Lancet. 2005; 365(9453): 36-42. doi: 10.1016/S0140-6736(04)17663-0.

35) Dehghan H, Charkazi A, Kouchaki GM, Zadeh BP, Dehghan BA, Matlabi M, Mansourian M, Qorbani M, Safari O, Pashaei T, Mehr BR. General self-efficacy and diabetes management self-efficacy of diabetic patients referred to diabetes clinic of Aq Qala, North of Iran. Journal of Diabetes \& Metabolic Disorders. 2017 Feb 15;16(1):8. doi: 10.1186/s40200-016-0285-z, PMid: 28239598, PMCid: PMC5312542

36) Farvid MS, Rabiee S, Homayoni F, Rashidkhani B, Arian V. Determinants of fruit and vegetable consumption in type 2 diabetics in Tehran. Iranian J Endocrinology \& Metabolism. 2010; 12(2): 89-98.

37) Dastgiri S, Mahboob S, Tutunchi H, Ostadrahimi A. Determinants of food insecurity: a cross-sectional study in Tabriz. J Ardabil Univ Med Scie. 2006; 6(3): 233-9.

38) Dunn KI, Mohr P, Wilson CJ, Wittert GA. Determinants of fast-food consumption. An application of the Theory of Planned Behaviour. Appetite. 2011; 57(2): 349-57. doi: 10.1016/j.appet.2011.06.004. PMID: 21683749.

39) Brannon L, Feist J. Health psychology: an introduction to behaviour and health. 7th ed. Wadsworth CENGAGE learning; 2010: 43-67. 